\title{
Analysis of three decades of research in marine sciences in Uruguay through mapping of science and bibliometric indexes
}

\author{
Diego Lercari ${ }^{1}$ \\ ${ }^{1}$ UNDECIMAR, Departamento de Ecología y Evolución, Facultad de Ciencias \\ Universidad de la República, Montevideo, Uruguay \\ Corresponding author: Diego Lercari (lercari@ fcien.edu.uy)
}

\begin{abstract}
Uruguay has recently expanded its Exclusive Economic Zone (EEZ), having more aquatic sovereignty than terrestrial territories. In this country, various State institutions have carried out the study of marine science for several decades, but their academic development has not been analyzed. The formal evaluation of scientific research represents a crucial opportunity to define long-term policies requiring greater knowledge of the territory and its resources. In this context, this work carries out a systematic and quantitative review of Uruguay authors' international publications over three decades. The productivity indicators trend is evaluated concerning context variables, predominant research topics are identified, and collaboration networks are characterized. We collected and analyzed data on marine science articles in which an author or co-author is affiliated to an institution in Uruguay from 1990 to 2018 using the Scopus database. It was found that scientific activity measured by a bibliographic analysis showed an increase in the number of articles, authors, and research topics but nowadays show signs of stagnation. Moreover, specific indicators show a great degree of centralism (institutional and authorial), low dynamism, and decreased international collaboration. The largest academic capacities are focused in specific biological disciplines, with little physics and almost nil in geology and chemistry. Decentralization and strengthening sectorial funding for marine science will boost Uruguay's discipline for facing future challenges.
\end{abstract}

Keywords: bibliometric analysis; marine science; research topics; collaboration networks; Uruguay

\section{INTRODUCTION}

Marine science deals with the scientific investigation of the oceans and seas of the Earth. It consists of a wide array of research fields converted into an interdisciplinary science that integrates physics, chemistry, biology, geology, and geography, among other disciplines. Studies in marine science allow the fundamental understanding of marine ecosystems' structure and functioning and provide tools for the analysis of various problems related to those environments. For example, the construction of infrastructure, fisheries management, the evaluation of the effects of pollution, and climate change consequences are based on scientific knowledge.

In this broad sense, marine studies in Uruguay can be traced back to the $16^{\text {th }}$ century explorers, when the marine cartography was sketched, and the patterns of winds and marine currents were described. Later, diffe- rent scientific expeditions (e.g. Malaspina during 17891794 or Darwin in 1832) deepened knowledge of marine fauna and generated environmental descriptions. Some $18^{\text {th }}$-century Uruguayan naturalists, such as Dámaso Antonio Larrañaga, provided valuable knowledge of the country's marine organisms. The foundation of the first academic institutions, the Museo Nacional de Historia Natural (MNHN) in 1837 and the Universidad de la República, (UDELAR) in 1849, could be considered the beginning of the systematization of the knowledge generated by the country, including several aspects considered today as marine science (Klappenbach \& Scarabino 1969). In the first decades of the $20^{\text {th }}$ century, the generation of hydrographic knowledge (physical oceanography and meteorology) was entrusted to the Servicio de Oceanografía, Hidrografía y Meteorología de la Armada (SOHMA), an institution created in 1916 that continues today. During the $20^{\text {th }}$ century, thanks to industrialization

Corresponding editor: Fernando Vega 
and increased fishing activity, information was generated on the system, fishing resources, their potential and limitations, and a regulatory and institutional framework was formed as well (Marin 2017). Beyond what was done autonomously by UDELAR, the study of fisheries by the government was in charge of a long succession of institutions: the Instituto de Pesca in 1911, the Servicio de Oceanografía y Pesca in 1933, the Servicio Oceanográfico y de Pesca (SOYP) in 1945, the Industrias Loberas y Pesqueras del Estado (ILPE) in 1975, the Instituto Nacional de Pesca (INAPE) in 1991, and from 2000 to the present time, the Dirección Nacional de Recursos Acuáticos (DINARA). These institutions generated basic knowledge related to marine science based on their infrastructure (e.g. research vessels) and direct access to fisheries information.

Since the 1970s, the study of marine science has flourished as promoted by the granting of the 200 miles Exclusive Economic Zone (EEZ) of Uruguay, the Treaty of the Río de la Plata (1973), and the establishment of a National Plan of Fisheries Development in 1975 (Bertullo 2005). Almost coincidentally, educational opportunities related to marine science were offered. At the secondary level, there was the Escuela de Industrias Navales (Universidad del Trabajo del Uruguay) since 1938, which also offers careers related to fishing (Professional Bachelor of Fishing). UDELAR created the Instituto de Investigaciones Pesqueras of the Veterinary Faculty (1961), and in the Faculty of Humanities and Sciences, at the tertiary level, the Bachelor of Biological Oceanography was taught from 1978 to 1986 , training more than 120 professionals. In 1986, the School of Engineering created the Instituto de Mecánica de Fluidos e Ingeniería Ambiental (IMFIA). Postgraduate courses related to marine disciplines began in the early 1990s, thanks to the Faculty of Sciences (within the UDELAR) and the creation of the Programa de Desarrollo de las Ciencias Básicas (PEDECIBA), an inter-institutional program, with UNDP (United Nations Development Programme) participation, focused on scientific development through high-level training. From that time, these institutions remained mostly unchanged and began to follow international standards of academic productivity based on referred articles' publication.

Recently, the interest in marine science in Uruguay has increased, notably due to different coinciding factors. On the one hand, the assignation of more surface area of the EEZ (Commission on the Limits of the Continental Shelf, 2016) and offshore resources' prospection presupposes a larger usufruct of ecosystem services. On the other hand, specific biological and environmental indicators (e.g. exploited populations, algal blooms, and pollutants) have generated alarm for the state of marine ecosystems and their biological resources (García-Alonso et al. 2019). Responding to those concerns, different academic actors in Uruguay promote greater efforts to further develop marine science as one of the most significant strategic importance.

In that context, for adequate and efficient planning, the value of understanding how knowledge is produced in a particular discipline or a specific geographical region has been recognized (Charles 2017). Thus, it is valuable to analyze who are the people undertaking investigations, what the predominant areas under investigation are, and how to understand the dynamics of the investigation, quantifying when and how much science is produced on research articles. In other words, it is essential to review what has been published to date and determine the progress made to delineate future strategies within the framework of an administration based on scientific evidence (Rousseau 2012). For that reason, the quantitative analysis of the publications of an academic community (bibliometric approach) is widely accepted to evaluate trends and patterns in most areas of scientific research (Moody \& Light 2006, Edelman et al. 2017, Borrett et al. 2018). However, in Latin America, this type of analysis is scarce in natural sciences (but see Boltovskoy \& Valentin 2018, Nielsen-Muñoz et al. 2018) and, in particular, nonexistent in Uruguay for the case of marine science.

Based on this background, it is proposed here to carry out a systematic and quantitative review of Uruguayan authors' international publications over three decades to evaluate the development and status of marine science in Uruguay. Specifically, the following objectives are proposed: 1) analyze scientific bibliographic production over time, evaluating its key features (e.g. number of articles, number of co-authors, citations, and basic indexes) and their relationship with context variables (e.g. gross domestic product (GDP) and thesis generation), 2) identify the predominant research topics in the different decades studied, and 3) characterize the dynamics of the collaborative networks of the research teams.

This work seeks to synthesize the key aspects of scientific publications to evaluate the strengths and weaknesses of the academic community of Uruguay's marine science. The results obtained are among the first examples of quantitative evaluation of an academic community's structure and functioning in Uruguay, exemplifying how a systematic, objective and reproducible approach would support marine science research planning. 


\section{MATERIALS AND METHODS}

\section{Case study}

The work is carried out at the country level, concentrating primarily on the bibliometric analysis of Uruguay's marine science topics from 1990 to 2018.

In size, Uruguay is a small country of $176,000 \mathrm{~km}^{2}$ (ranked 91 worldwide) and is relatively sparsely populated $\left(3,400,000\right.$ inhabitants, $134^{\text {th }}$ place $)$. Its economy is based on the export of soybeans, meat, and pulp, reaching a GDP per capita of USD 23,571 (ranked 58). Although it has a coastline exceeding $650 \mathrm{~km}$ and a marine EEZ of $206,000 \mathrm{~km}^{2}$, the country historically and culturally has not paid attention to the marine environment in comparison with attention paid to the mainland (Santini 2011). For example, the per capita annual consumption of fish according to FAO $(\sim 8 \mathrm{~kg})$ is much lower than the world average $(\sim 20 \mathrm{~kg})$, and fishing contributes on average only $0.12 \%$ to the country's GDP (according to data from the Central Bank of Uruguay). Since 2008, Uruguay has had a National System of Researchers comprised of 1500 scientists, approximately 500 researchers per million inhabitants (ranked 58 according to UNESCO 2015). The state's spending on science is $0.35 \%$ of GDP, half of the Latin American average and almost six times less than what is spent in developed countries (UNESCO 2015). That percentage has not appreciably changed in the last years.

Regarding the institutional arrangement, more than 90\% of academics carry out their work in State agencies. Of those, the majority belongs to the UDELAR, the major public university in the country (ranked 31 among Latin American universities) characterized as having the broadest autonomy in management and power in research and teaching. The government's direct participation in research (approximately $20 \%$ of the researchers) is carried out by research centres dependent on the Ministries (e.g. Instituto de Investigaciones Biológicas Clemente Estable (IIBCE), DINARA).

\section{Data mining}

The publications analyzed correspond to Scopus of the Elsevier publishing house, the largest database of references from peer-reviewed international literature, including journals, books, and proceedings. Although there are other bibliographic information sources, Scopus was chosen since access to this database is guaranteed by the State of Uruguay, which subsidizes the subscription annually for all country citizens.

For this work, we sought to obtain a collection that included as many publications as possible made by researchers with Uruguayan affiliation in the different fields of the marine sciences. To capture the patterns of international collaboration, we sought to include works by Uruguayan researchers regardless of whether the study was conducted in Uruguayan territory or not.

First, the following search chain for references was applied in the Scopus web interface, seeking to capture the different disciplines included in marine science:

\section{All (marine) and affilcountry (Uruguay)}

In that way, manuscripts that included "Uruguay" in the affiliation field and the word "marine" in any of all the considered fields (i.e. title, abstract, keywords) were added to the collection, resulting in 1741 documents. In a second instance, the first collection's references were manually reviewed one by one to ensure their quality and relevance. Only those scientific studies of any area of knowledge focused on some marine systems were included in this process. The membership of an article to the marine science discipline was ensured by the following criteria: marine biology (all levels of the organization), fisheries and aquaculture, paleontology, physical oceanography and meteorology, chemical and geological oceanography, marine engineering, manage-ment, and marine governance as well as multidisci-plinary studies.

During this step, duplicate references were eliminated, and the authors' names that appear in two or more different forms were unified. No secondary Scopus documents were considered (i.e. those that may be extracted from a Scopus document reference list but is not available directly in the Scopus database). The resulting collection is available upon request to the author.

Finally, for each article chosen, the bibliographic information was collected, including the title, authors, abstract, keywords, year of publication, source (journal details), and cited references. The collection so obtained was divided into three period's representative of each decade: 1990 to 1999,2000 to 2009, and 2010 to 2018 , to evaluate the temporal evolution.

\section{Global description and temporal analysis}

The collection obtained was descriptively evaluated using several bibliometric indexes. The total number of articles during the analyzed period, the average growth rate, the total number of authors, and various combined indexes (e.g. authors per article) were considered. The institutions and authors with the most significant presence in the articles were determined. Those articles and authors mostly cited throughout the study period were identified. 
Impact indexes of authors with higher productivity were analyzed in each of the decades studied and for the entire study period. The $h$ index (Hirsch 2005) represents the balance between the number of publications and their citations. It is estimated by ordering (in descending order) the publications by the number of citations received, listing them to identify the point at which the order number matches the number of citations received by a publication. On the other hand, the g index (Egghe 2006) considers the number of citations received by the articles that are part of the $h$ core: the volume of the most cited articles considered for calculating the $\mathrm{h}$ index, which is estimated by ordering the articles of an author in descending order according to the number of citations received by each of them (the same as the $h$ index), and the $\mathrm{g}$ index is identified as the highest number of order in the ranking, where the sum of citations received by the author is greater than or equal to the square of the order number. Other author indicators estimated were: total citations (TC), multi-author articles (MA), articles as first author (FA), and the dominance factor (DF), which indicates the fraction of multi-authored articles in which a scholar appears as the first author (i.e. DF = MA / FA).

Temporal trends in the number of publications throughout the period were analyzed, and the dependence between the number of articles per year and economic, productive, and academic indicators of Uruguay were modelled by generalized linear models (GLMs, McCullagh \& Nelder 1989). The independent variables considered were the annual GDP of Uruguay (official statistics of the Central Bank of Uruguay), the budget of the University of the Republic (official UDELAR data), the \% of GDP generated by fishing, the $\%$ of GDP generated by maritime transport (official statistics of the Central Bank of Uruguay), the global quantity of articles in marine science (generated by a global search in Scopus) and the number of thesis in marine science published in Uruguay (UDELAR bibliographic database). Some other potential explanatory variables were excluded from the analysis after multicollinearity detection (e.g. per capita GDP, fisheries landings) following Pearson correlation analysis). Poisson models and a log-link function were used for fitting. Because of potential correlations among covariates, variables were dropped one at a time, and the best subset was chosen following Akaike's information criterion (AIC). Residual plots and deviance were evaluated for violations of model assumptions.

\section{Research topics: a co-word analysis}

The primary sources (journals), where the authors with affiliation from Uruguay published, and the temporal change over the period studied were determined to delineate the conceptual axes of marine science. On the other hand, the articles' keyword co-occurrences were mapped (Courtial et al. 1991); this approach reveals patterns and trends of scientific research areas, measuring the association's strength between the terms. In this way, a map of a given scientific field's conceptual structure is produced (Delecroix \& Eppstein 2004). The keywords included in the entire database were identified and ordered based on their frequency of appearance. A conceptual map was made based on the analysis of the co-occurrence of words (in the titles, keywords, and abstracts of the articles) to identify predominant research areas in different time series periods.

\section{Collaboration networks: co-authorships analysis}

Personal interactions among scientists are essential for academic advancement, and to no small extent, the coauthorship of articles reflects the degree of collaboration between them (Melin \& Persson 1996). In this work, using the list of co-authors, a network was implemented that captures the research system's properties and the influence of the bibliometric units, allowing the intellectual structure of the discipline in Uruguay to be defined (Peters \& Van Raan 1991). Through this approach, the different groups of researchers and the collaboration flow between them and foreign authors were visualized in the different periods of the analyzed time series.

To develop the quantitative bibliometric analysis of the collections of bibliographic references, the $\mathrm{R}$ program (R Core Team 2016) was used. In particular, the specialized bibliometric package was employed (Aria \& Cuccurullo 2017). Mapping the co-word and co-author networks were performed with the VOSviewer program (Van Eck \& Waltman 2007).

\section{RESULTS}

\section{Global description and temporal analysis}

During the analyzed period (28 years), Uruguayan authors published almost 900 articles referring to marine science in journals registered in the Scopus database. The period includes the outbreak of international refereed publications on this subject in the country since in 1990 only four papers were published in journals indexed in the Scopus database. From that moment on, the number of published articles steadily increased (Fig. 1), reaching more than 80 articles per year and presenting an annual increase rate of $10.4 \%$. However, this growth shows stagnation signs from the year 2014. 


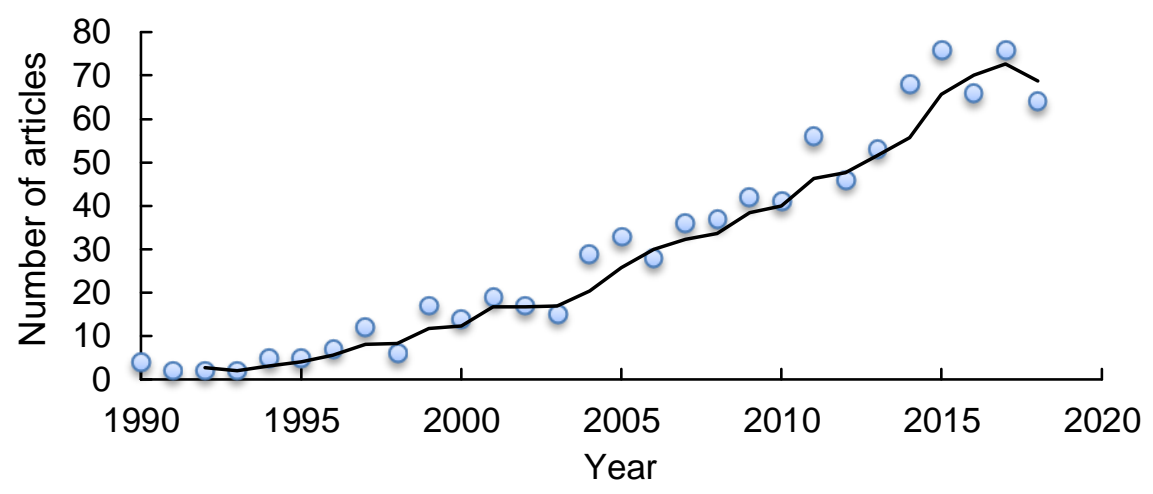

Figure 1. The annual number of scientific articles in marine science produced by authors with Uruguayan affiliation registered in Scopus from 1990 to 2018. Three years running mean (black line) is also shown.

The model resulting with the lowest AIC related the number of articles with GDP, the university budget, the number of published thesis in marine science, and the global number of articles in oceanographic science $\left(\right.$ AIC $=161.12 \log$ ratio $\left.X^{2}=241.04, P<0.01\right)$. However, only GDP, the university's budget, and the global number of articles in oceanographic science resulted in significant associations (Table 1).

Specific bibliometric indicators estimated for each decade also showed an increase over the period (Table 2). For example, the number of sources (different journals) was multiplied by 7 , while the number of authors (including foreign co-authors) was multiplied by 17 , and the number of co-authors and the collaboration index doubled. By contrast, other indicators decreased over time; for example, the average citations of publications (expected because a document receives fewer citations over time) and the number of documents per author. It highlights the low number of publications with a single author, 18 throughout the period.

Regarding the most frequently cited articles, there is a substantial increase in the citations received during the periods and the citations received per year (Table $3)$. In the first decade, on average, the first five most cited articles received 134 citations ( 6 per year); between 2000 and 2009, the first five articles received 341 citations ( $\sim 34$ per year), and in the most recent decade, the first five articles received 448 citations ( $\sim 50$ per year). We can distinguish that several of the most cited articles correspond to foreign authors excepting the first decade, with Uruguayan affiliations acting as co-authors. On the other hand, in the most recent decade, the article with the highest number of citations corresponds to a first author from Uruguay. The main topics and sources of the most cited articles varied over time.

Only three institutions are frequently mentioned as affiliations involved in the generation of knowledge in marine science in Uruguay over the decades (Table 4). The UDELAR appears the most important institution in Uruguay in scientific articles production in marine science, being mentioned between 35\% (1990-1999) and 56\% (2010-2018) and demonstrating an increase in its institutional dominance. It is followed by the National Fisheries Management Institute INAPE/ DINARA of the Ministerio de Ganadería Agricultura y Pesca (MGAP), the scientific bibliographic production of which ranged from $21 \%$ (1990-1999) to $19 \%$ in the most recent decade. For its part, the MNHN of the Ministerio de Educación y Cultura (MEC) has significantly increased its participation in the generation of publications from 1990-1999 (less than 1\%) to more than $6 \%$ in the past decade.

Additionally, the number of institutions participating in marine science, doubling from 1990-1999 to 2009-2018, highlights incorporating other organizations such as NGOs and public companies. The participation of foreign institutions in articles decreased concerning the total number of institutions mentioned in the collection, going from almost 40\% (1990-1999) to $51 \%$ (1999-2008) and declining to $18 \%$ in the last decade analyzed.

The most productive author in all periods analyzed is Omar Defeo (UDELAR and DINARA), who shows the highest values in all the indexes and periods analyzed, except for the DF indicator. In the first period, some notable authors did not maintain their position in the following two decades (e.g. Zulema Coppes from UDELAR). During the decades of 20002009 and 2010-2018, the principal four authors remained: Walter Norbis (UDELAR and DINARA), Felipe García-Rodríguez, Pablo Muniz and Alvar Carranza (UDELAR), changing only in order according to the $\mathrm{h}$ index. Another aspect highlighted is the decrease in the frequency of appearance as the first author of the five principal authors, producing a general decrease in the DF (Table 5). 
Table 1. Parameter estimates of the best model. Generalized linear models (GLM) coefficient estimates (mean and standard error) are shown together with the Wald statistic and $P$-value. GDP: gross domestic product. SE: standard error.

\begin{tabular}{lrrrc}
\hline & Estimate & SE & Wald statistic & $P$ \\
\hline Intercept & 2.393163 & 0.398 & 36.1 & 0.000 \\
GDP & 0.000000 & 0.000 & 7.3 & 0.007 \\
University Budget & -0.000003 & 0.000 & 7.7 & 0.006 \\
Thesis in marine sciences & 0.015593 & 0.011 & 2.0 & 0.155 \\
Global articles in oceanography & 0.000140 & 0.000 & 7.6 & 0.006 \\
\%GDP due to fishing & 0.759412 & 1.633 & 0.2 & 0.642 \\
\%GDP due to marine transportation & -0.230842 & 0.514 & 0.2 & 0.654 \\
\hline
\end{tabular}

Table 2. Bibliometric description of marine sciences in Uruguay in the last three decades. Full studied period details are also displayed. *Includes all the authors in the collection, not only those with Uruguayan affiliation.

\begin{tabular}{lcccc}
\hline & \multicolumn{4}{c}{ Period } \\
\cline { 2 - 5 } & $1990-1999$ & $2000-2009$ & $2010-2018$ & $1990-2018$ \\
\hline Number of documents & 62 & 270 & 546 & 878 \\
Sources (journals, books) & 34 & 126 & 241 & 322 \\
Keywords plus & 381 & 1865 & 3599 & 4749 \\
Author's keywords & 141 & 719 & 1535 & 2140 \\
Average citations per documents & 34 & 33.51 & 12.79 & 20.58 \\
\hline Authors * & 111 & 541 & 1906 & 2319 \\
Author appearances & 180 & 1025 & 3418 & 4623 \\
Authors of single-authored documents & 7 & 4 & 8 & 18 \\
Authors of multi-authored documents & 104 & 537 & 1898 & 2301 \\
\hline Documents per author & 0.559 & 0.499 & 0.29 & 0.379 \\
Authors per document & 1.79 & 2 & 3.49 & 2.64 \\
Co-authors per documents & 2.9 & 3.8 & 6.26 & 5.27 \\
Collaboration index & 1.93 & 2.05 & 3.53 & 2.7 \\
\hline Annual growth rate $(\%)$ & 17.44 & 12.98 & 5.72 & 10.4 \\
\hline
\end{tabular}

\section{Research topics: a co-word analysis}

The keyword co-occurrence network (Fig. 2a) during 1990-1999 stands out for its simplicity. It includes 76 words forming five clusters of research topics: two clusters seem related to the ecology of sandy beaches and fisheries management, another group included general concepts of fish biology; a fourth cluster included names of some commercial fish species, and the last one involves aspects of climate change and coastal erosion. The groupings are discrete (there is no great overlap between the clusters) and relatively poorly interconnected. During the decade 2000-2009 (Fig. 2b), the keyword co-occurrence network is notoriously more complex, covering 112 items, and although it is possible to find six groups, they do not remain the same as in the previous period. Additionally, the development of the network is evident, adding more words to each group. The clusters of fish biology and beach ecology were developed with more topics. A new large cluster was developed covering pollution, microbiology, controlled studies. Three small clusters emerge, one focused on Copepoda, the other on
Bacillariophyta, and the other on coastal engineering. The groupings remain highly discrete (there is no great overlap between the clusters) but with a greater number of connections. In the last period analyzed (2010-2018) (Fig. 2c), the complexity level is even greater, with new keywords appearing and a new grouping totalling six clusters. The group with the largest number of concepts is related to sandy beaches, estuarine environments, and coastal lagoons, including various biodiversity descriptors. A large grouping is related to fisheries and the large vertebrates (mammals, birds). The fish biology group appears next to genetics and physiology populations' dynamics and biodiversity. A smaller cluster, with 25 items, covers sea turtle concepts. The last grouping includes climatic change and physical oceanography. In this decade, a more significant interrelation and overlap between the groups becomes evident.

During the first period studied (1990-1999), several of the used sources are related to food production based on fisheries and aquaculture (Table 6). Journals focused on marine ecology and, mainly related to coastal and 
Table 3. Articles produced by Uruguayan authors/co-authors with the highest number of citations received (TC: total citations) each decade and the entire period studied. The number of cites per year $(\mathrm{C} / \mathrm{y})$ is also shown, and a disciplinary theme is mentioned.

\begin{tabular}{llcc}
\hline Period (1990-1999) & Source & TC & C/y \\
\hline Díaz et al. (1998) & Journal of Climate (physical oceanography) & 162 & 7.7 \\
Bessonart et al. (1999) & Aquaculture (aquaculture) & 137 & 6.9 \\
Defeo et al. (1992) & Journal of Coastal Research (sandy beaches ecology) & 134 & 5.0 \\
McLachlan et al. (1996) & Oceanography and Marine Biology (sandy beaches ecology) & 129 & 5.6 \\
Defeo \& De Alava (1995) & Marine Ecology Progress Series (sandy beaches ecology) & 108 & 4.5 \\
\hline Period (2000-2009) & Source & TC & C/y \\
\hline Defeo et al. (2009) & Estuarine, Coastal and Shelf Science (sandy beaches ecology) & 533 & 53.3 \\
Dulvy et al. (2008) & Aquatic Conservation: Marine and Freshwater Ecosystems (conservation) & 415 & 37.7 \\
Defeo \& McLachlan & Marine Ecology Progress Series (sandy beaches ecology) & 279 & 19.9 \\
Piola et al. (2000) & Journal of Geophysical Research: Oceans (physical oceanography) & 250 & 13.2 \\
Schlacher et al. (2007) & Diversity and distributions (sandy beaches ecology) & 229 & 19.1 \\
\hline Period (2010-2018) & Source & TC & C/y \\
\hline Gutiérrez et al. (2011) & Nature (fisheries) & 604 & 75.5 \\
Beck et al. (2011) & Bioscience (species conservation) & 423 & 52.8 \\
Gelcich et al. (2010) & Proceedings of the National Academy of Sciences (fisheries) & 258 & 28.7 \\
Miloslavich et al. (2011) & Plos One (marine biodiversity) & 117 & 14.6 \\
Vegter et al. (2014) & Endangered Species Research (species conservation) & 104 & 20.8 \\
\hline Period (1990-2018) & Source & TC & C/y \\
\hline Gutiérrez et al. (2011) & Nature (fisheries) & 600 & 75 \\
Defeo et al. (2009) & Estuarine, Coastal and Shelf Science (sandy beaches ecology) & 529 & 52.9 \\
Dulvy et al. (2008) & Aquatic Conservation: Marine and Freshwater Ecosystems (conservation) & 414 & 37.6 \\
Beck et al. (2011) & Bioscience (species conservation) & 420 & 52.5 \\
Defeo \& McLachlan (2005) & Marine Ecology Progress Series (sandy beaches ecology) & 279 & 19.9 \\
\hline & & &
\end{tabular}

estuarine environments, begin to appear. In the following decade (2000-2009), sources focusing on marine science's fundamental aspects, mainly ecology and marine biology, become more relevant. Sources related to productive aspects continue to be used but to a lesser extent while specialized journals are also employed (e.g. pollution). In the most recent period (2010-2018), Uruguayan authors' publications appear in regional sources, but also articles are published in general journals of marine biology, estuaries, and pollution.

\section{Collaboration networks: co-authorships analysis}

The development of scientific collaboration networks is shown (Fig. 3). In the first decade (Fig. 3a), the coauthorship network reveals different sub-networks of completely disconnected authors and, in many cases, comprised of very few authors. In larger groups, coauthorship with foreign research groups becomes evident, while groups with fewer co-authors appear virtually isolated. In the larger groups, centralization of the production of articles is observed by works of authors with more publications. In the period 20002009 , new clusters of authors appear, keeping to a large extent those already existing (although some were merged or disappeared). There is an increase in foreign collaboration networks in almost all clusters and a greater relationship between local clusters. In the most recent decade, the beginning of articles' production by new authors is observed, but there is a decrease in groupings. The predominance of some authors is also evident in this period. There is an increase in the interconnection between authors' groupings and a more significant overlap between the co-author's clusters.

\section{DISCUSSION}

In this work, a holistic review of the development of the publications in marine science by Uruguayan authors was carried out, being one of the first of its kind in Latin America. The analysis captured the academic beginning of this discipline and reflected an overall increase in peer-reviewed scientific publications, reaching more than 70 articles per year during the most recent period.

\section{Global description and temporal analysis}

The general increase in Uruguayan authors' publications in marine science coincides roughly with the trends found in all scientific disciplines worldwide 
Table 4. The number of mentions (in the bibliographic field "affiliation") to the different Uruguayan institutions with publications in marine sciences in the three analyzed periods. The number of mentions to foreign institutions is also shown.

\begin{tabular}{lr}
\hline Period & Mention \\
\hline 1990-1999 & 34 \\
Universidad de la República (UDELAR) & 21 \\
Instituto Nacional de Pesca (INAPE) & 2 \\
Museo Nacional de Historia Natural (MNHN) & 2 \\
Comisión Nacional de Cambio Climático & 1 \\
Dirección Nacional de Medio Ambiente (DINAMA) & 38 \\
Foreign institutions & \\
$\mathbf{2 0 0 0 - 2 0 0 9}$ & 240 \\
Universidad de la República (UDELAR) & 48 \\
Instituto Nacional de Pesca (INAPE)/Dirección Nacional de Recursos Acuáticos (DINARA) & 8 \\
National Museum of Natural History & 6 \\
Instituto de Investigaciones Biológicas Clemente Estable (IIBCE) & 4 \\
Centro de Investigación y Conservación Marina (CICMAR) & 2 \\
Proyecto Albatros y Petreles & 1 \\
Dirección Nacional de Medio Ambiente (DINAMA) & 2 \\
Karumbé & 326 \\
Foreign institutions & \\
$\mathbf{2 0 1 0 - 2 0 1 8}$ & 485 \\
Universidad de la República (UDELAR) & 92 \\
Dirección Nacional de Recursos Acuáticos (DINARA) & 55 \\
Museo Nacional de Historia Natural (MNHN) & 26 \\
Centro Universitario Regional Este (CURE-UDELAR) & 19 \\
Instituto de Investigaciones Biológicas Clemente Estable (IIBCE) & 42 \\
Centro de Investigación y Conservación Marina (CICMAR) & 11 \\
Proyecto Albatros y Petreles & 7 \\
Karumbé & 123 \\
Foreign institutions & \\
\hline
\end{tabular}

(Price 1961, Tabah 1999), but in the present study, the growth slowdowns in the last five years. The earlier linear trend found is coincident, for example, with that reported worldwide for fisheries science (Aksnes \& Browman 2016).

However, after more than 20 years of constant growth, the publication number's development shows stagnation signs. In this sense, these results could be interpreted as that Uruguay's marine science is constrained by some factors such as the accessibility to expensive oceanographic equipment (Lauro et al. 2014, Boltovskoy \& Valentin 2018). However, the limited number of new permanent working positions in fields related to marine sciences, the "dispersion" of the research groups and areas, and the lack of a university degree in marine science or oceanography may also contribute to the observed stagnancy.

Other indicators of development of the discipline analyzed in this paper show an increase in scientific collaboration, for example, the duplication of the collaboration index, the decrease of several documents per author, the increase of articles written by a single author, and the complexity of the networks of coauthorships (see below).

In Uruguay's case, the increase in the number of articles was significantly correlated with the UDELAR budget. The strong correlation between economic growth indicators and the increase in the number of publications in marine science (IOC-UNESCO 2017) has been demonstrated at a global level. Although direct cause-effect relationships cannot be established with the available information, it is logical to think that the increase in economic and human resources by the institution, which is the principal producer of articles in the area, leads to an increase in scientific bibliographic production. The positive consequences of greater resources dedicated to science have been widely documented (Frazzetto 2004, Bornmann \& Mutz 2015). In this case, the budget increase may have encouraged the initial incorporation of human resources, leading to many authors publishing in the discipline and incorporating foreign co-authors due to international collaboration. However, marine science research funding has been uneven and generally low in the southwest Atlantic region (Boltosvkoy \& Valentin 
Table 5. Bibliometric indexes of the five principal authors in Uruguay's marine sciences (sorted by the $\mathrm{h}$ index) during the last three decades and in the total period analyzed g: g index, m: $\mathrm{m}$ index, TC: total citations, DF: dominance factor, MA: multi-author articles, FA: first author. Scale of colors: major red, minor green.

\begin{tabular}{|c|c|c|c|c|c|c|c|c|}
\hline \multicolumn{9}{|c|}{ 1990-1999 } \\
\hline & Author & $\mathrm{h}$ & $\mathrm{g}$ & $\mathrm{m}$ & $\mathrm{TC}$ & $\mathrm{DF}$ & MA & FA \\
\hline 1 & Defeo, O. & 13 & 18 & 0.45 & 995 & 0.389 & 18 & 7 \\
\hline 2 & Norbis, W. & 5 & 6 & 0.19 & 156 & 0.2 & 5 & 1 \\
\hline 3 & Brazeiro, A. & 4 & 5 & 0.17 & 225 & 0.75 & 4 & 3 \\
\hline 4 & Coppes, Z. & 4 & 4 & 0.15 & 115 & 1 & 2 & 2 \\
\hline 5 & Pavlisko, A. & 4 & 4 & 0.17 & 59 & 1 & 4 & 4 \\
\hline \multicolumn{9}{|c|}{$2000-2009$} \\
\hline & Author & $\mathrm{h}$ & $\mathrm{g}$ & $\mathrm{m}$ & $\mathrm{TC}$ & DF & MA & FA \\
\hline 1 & Defeo, O. & 26 & 46 & 1.3 & 2471 & 0.206 & 68 & 14 \\
\hline 2 & Giménez, L. & 15 & 20 & 0.75 & 634 & 0.5 & 16 & 8 \\
\hline 3 & Carranza, A. & 9 & 17 & 0.6 & 326 & 0.76 & 17 & 13 \\
\hline 4 & Muniz, P. & 15 & 17 & 0.75 & 717 & 0.47 & 17 & 8 \\
\hline 5 & Calliari, D. & 9 & 12 & 0.474 & 296 & 0.76 & 13 & 10 \\
\hline \multicolumn{9}{|c|}{ 2010-2018 } \\
\hline & Author & $\mathrm{h}$ & $\mathrm{g}$ & M & TC & DF & MA & FA \\
\hline 1 & Defeo, O. & 22 & 48 & 2.2 & 2444 & 0.1 & 69 & 7 \\
\hline 2 & Domingo, A. & 13 & 22 & 1.3 & 548 & 0.08 & 37 & 3 \\
\hline 3 & Muniz, $P$. & 12 & 18 & 1.2 & 422 & 0.19 & 42 & 8 \\
\hline 4 & Carranza, A. & 9 & 26 & 0.9 & 716 & 0.18 & 34 & 6 \\
\hline 5 & García-Rodríguez, F. & 9 & 14 & 0.9 & 226 & 0.125 & 24 & 3 \\
\hline \multicolumn{9}{|c|}{$1990-2018$} \\
\hline & Author & $\mathrm{h}$ & $\mathrm{g}$ & M & TC & DF & MA & FA \\
\hline 1 & Defeo, O. & 37 & 74 & 1.276 & 5892 & 0.19 & 133 & 25 \\
\hline 2 & Muniz, $\mathrm{P}$. & 22 & 33 & 0.917 & 1195 & 0.3 & 61 & 18 \\
\hline 3 & Carranza, A. & 14 & 31 & 0.933 & 1034 & 0.37 & 51 & 19 \\
\hline 4 & Domingo, A. & 17 & 33 & 1.133 & 1173 & 0.09 & 46 & 4 \\
\hline 5 & Norbis, W. & 15 & 20 & 0.556 & 502 & 0.09 & 45 & 4 \\
\hline
\end{tabular}

2018), and Uruguay is not an exception. Resources have been increasing over time, but the national agencies' research grants seem to be not enough to maintain the growth rate in scientific bibliographic production in resource-demanding disciplines as marine science.

Concerning the most cited articles, an increase was observed in the citations received per year (Table 3), reaching three times more in the last decade, showing greater dynamism in the discipline, which is also consistent with the increase in international collaboration (see below) as cooperation leads to an increase in citations received (Adams 2013). On the other hand, the decrease in the authors' leadership with Uruguayan affiliation throughout the study period, appearing less frequently as principal authors in the most recent decades, is evident. The sources and research topics of the most cited articles anticipate the relative role of the different disciplines that make up marine science in Uruguay. In the first decade, sandy beaches' ecology was the central topic of three of the most cited five articles. In the second decade, the topics related to physical oceanography appear, while in the most recent decade, the topics were highly varied.

The institutional interest in subjects related to marine science also shows a growing development. Throughout the studied period, the university dominated the production of articles in marine science, and that leadership is even more evident in the last decade, where this institution was linked to more than $60 \%$ of the works. The above can be attributed to the constant budgetary increase of the UDELAR (2016) and its decentralization policy, thanks to which new research groups have been incorporated, with new infrastructure, dedicated to the investigation of topics related to the marine science (CDC 2008, Arocena 2017). However, state institutions (belonging to different ministries) showed different trends in scientific articles' production. On the one hand, the institution responsible for fisheries management under the Ministry of Livestock (INAPE/DINARA), of great importance in the first decade studied, abruptly decreased its participation in the generation of scientific articles. Although the causes of this decrease have not been studied, institutional weaknesses have been identified regarding human resources, such as decreased staff number, the lack of incentives to investigate, and the lack of training (MGAP 2009), which demonstrates the low priority given by Uruguay's public policies regarding the environment and marine resources.

On the other hand, the increase in MNHN participation during the last decade stands out. Thanks to a change in its management strategy (MEC 2014), this institution seeks to position itself again as a scientific articles producer. The results of those efforts are reflected in the present study. The increase in the number and diversity of organizations related to articles in marine science in Uruguay coincides with a greater interest in various sectors of the country (conservationists and producers) in the marine environment. This intention is reflected in the implementation of the Comisión Nacional de Oceanología (IMPO 2009).

The mention of foreign institutions notably increased in the second decade, but drop to half in the last period. It can only be interpreted as a diminution in international collaboration after important international projects were developed in the country (Martínez \& Fournier 1999). Also, the collaboration generated by young scientists performing their postgraduate studies abroad boosted foreign institutions' co-participation. For example, the most common foreign institutions mentioned for the second period were, among others, CINVESTAV Unidad Mérida, México (where O. 


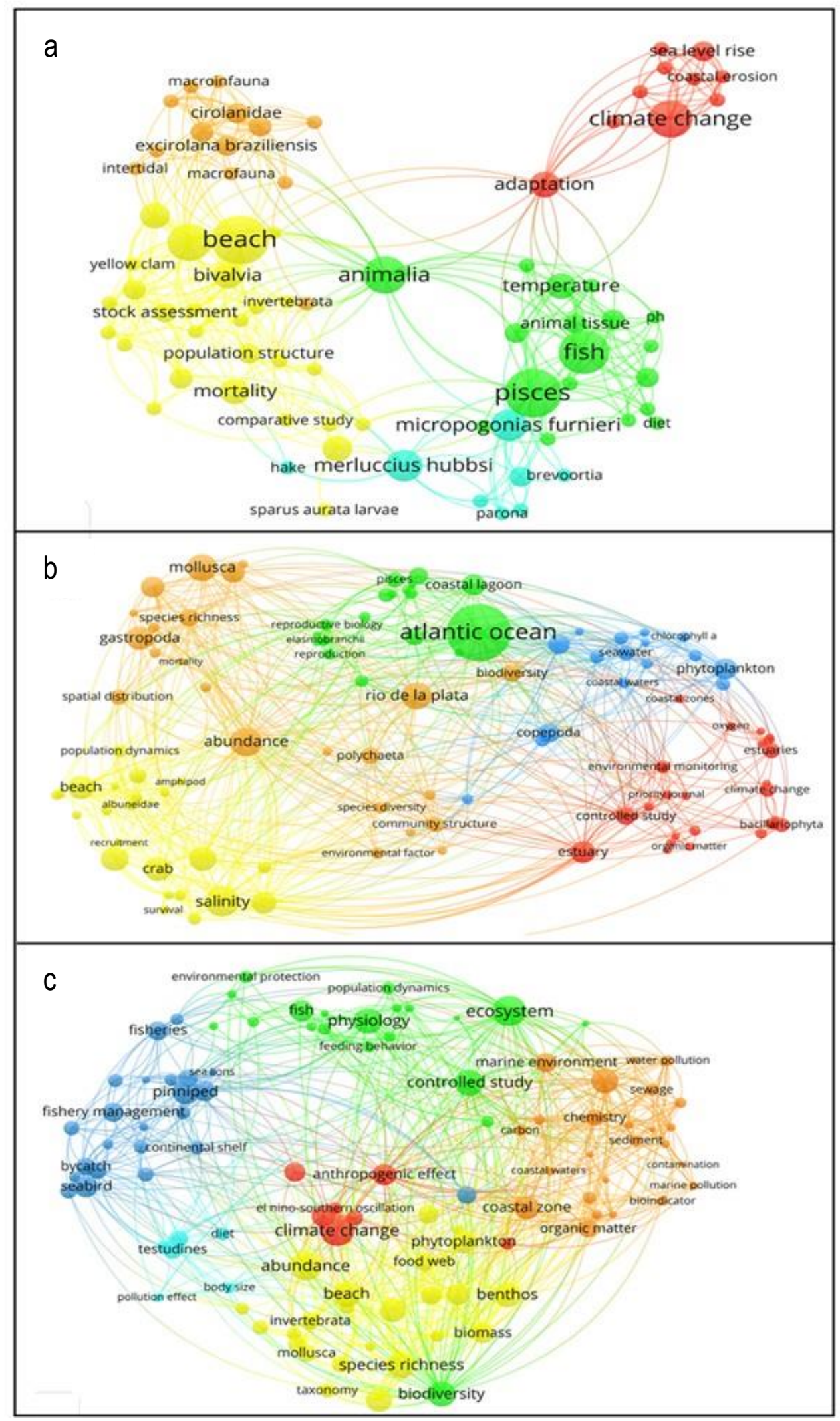

Figure 2. Visualization of the network of co-currencies of words in scientific articles of marine science produced by Uruguay authors in the last three decades. a) 1990-1999, b) 2000-2009, c) 2010-2018. Colors represent different clusters of keywords. 
Table 6. Most frequent sources (journals) of Uruguayan authors' publications in marine sciences discriminated in three periods analyzed. Primary sources for the entire study period are also showed.

\begin{tabular}{|c|c|}
\hline Period (1990-1999) & Articles \\
\hline Fisheries Research & 7 \\
\hline Climate Research & 5 \\
\hline Estuarine Coastal and Shelf Science & 5 \\
\hline Journal of Food Biochemistry & 5 \\
\hline Comparative Biochemistry and Physiology - Part B & 4 \\
\hline Aquaculture & 3 \\
\hline Marine Ecology Progress Series & 3 \\
\hline Journal of Coastal Research & 2 \\
\hline Marine Biology & 2 \\
\hline Scientia Marina & 2 \\
\hline Period (2000-2009) & Articles \\
\hline Marine Ecology Progress Series & 22 \\
\hline Marine Biology & 11 \\
\hline Journal of the Marine Biological Association of the UK & 9 \\
\hline Marine Pollution Bulletin & 9 \\
\hline Estuarine Coastal and Shelf Science & 8 \\
\hline Journal of Applied Ichthyology & 8 \\
\hline Journal of Experimental Marine Biology and Ecology & 7 \\
\hline Scientia Marina & 7 \\
\hline Fisheries Research & 6 \\
\hline Aquatic Conservation: Marine and Freshwater Ecosystems & 5 \\
\hline Period (2010-2018) & Articles \\
\hline Brazilian Journal of Oceanography & 22 \\
\hline Estuarine Coastal and Shelf Science & 17 \\
\hline Marine Pollution Bulletin & 16 \\
\hline Marine Ecology Progress Series & 15 \\
\hline Pan-American Journal of Aquatic Sciences & 15 \\
\hline Plos One & 14 \\
\hline Fisheries Research & 11 \\
\hline Marine Biology & 10 \\
\hline Estuaries and Coasts & 8 \\
\hline Journal of Coastal Research & 7 \\
\hline Period (1990-2018) & Articles \\
\hline Marine Ecology Progress Series & 40 \\
\hline Estuarine Coastal and Shelf Science & 30 \\
\hline Marine Pollution Bulletin & 25 \\
\hline Fisheries Research & 24 \\
\hline Brazilian Journal of Oceanography & 23 \\
\hline Marine Biology & 23 \\
\hline Pan-American Journal of Aquatic Sciences & 19 \\
\hline Journal of Experimental Marine Biology and Ecology & 14 \\
\hline Plos One & 14 \\
\hline Journal of the Marine Biological Association of the UK & 13 \\
\hline
\end{tabular}

Defeo obtained his Docto-Mérida, México (where O. Defeo obtained his Docto-rate in 1993), Universidade de São Paulo, Brazil (where P. Muniz obtained his postgraduate studies since 1996), and the AlfredWegener-Institute, Germany (where L. Jimenez, developed his Doctoral Thesis).
The detailed analysis of the main author's indexes showed that during the whole study period, in Uruguay, there were very few authors concentrating most of the scientific bibliographic production in marine science. The most productive author in all periods analyzed is $\mathrm{O}$. Defeo, who leads the $\mathrm{h}$ index and the total number 


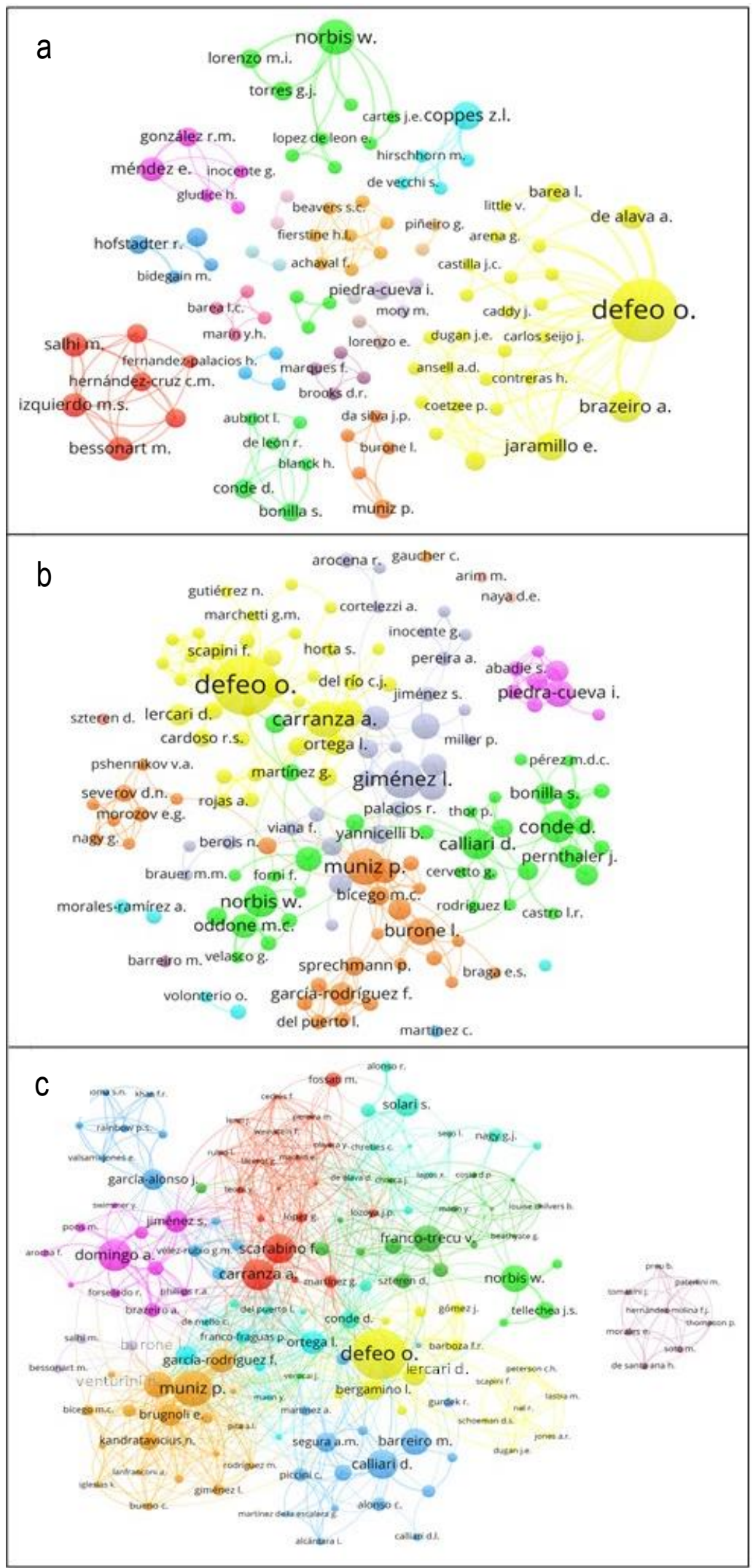

Figure 3. Visualization of the co-authorship network of the marine sciences of Uruguay discriminated in the three analyzed periods. a) 1990-1999, b) 2000-2009, c) 2010-2018. Colors represent different clusters of authors. 
of citations. The decade 1990-1999 had important authors who did not maintain their positions in the next two decades. During the decades of 2000-2009 and 2010-2018, most principal authors remained (W. Norbis, F. García-Rodríguez, P. Muniz and A. Carranza), changing only in order according to the $\mathrm{h}$ index. Another aspect being highlighted is the decrease in the frequency of appearing as the first author in the five principal authors, producing a general decrease in the degree of dominance, which implies that these authors appear less as first author and more as members of the group of co-authors.

\section{Research topics: a co-word analysis}

The words co-occurrence network analysis shows the development of marine science in Uruguay, where new research topics linked mainly to those already existing are emerging (Moody 2004). The different research topic clusters can be linked to the principal authors, particularly in the first two periods, where the coauthorship networks were not so complicated. In that sense, specific research topics were maintained from the beginning of the study (e.g. sandy beach ecology, fish biology, and pollution), others disappeared or merged (e.g. coastal engineering and coastal lagoons), and others emerged (e.g. estuarine ecology and vertebrate conservation). Beyond the subdisciplines, the predominance of biological areas in research stands out in the three decades. At present, there is a great advance in the knowledge of the benthic ecology of beaches, estuaries, and coastal lagoons. Environmental conditions and sediment are linked to different benthic taxonomic groups, environmental monitoring, and pollution. It can be affirmed that the analysis of the benthic ecology and the anthropic effects (combining the three main clusters of keywords) represents the greatest capacity of Uruguay in marine science. The population aspects related to the conservation of large vertebrates arise as a new large cluster related to fisheries issues (e.g. discards and management). Fish research appears mostly related to genetics and physiology issues rather than to fisheries. Although small clusters focused on physical and climatic processes can be identified in the different periods, the lack of research capabilities in many areas inherent to marine science is very evident. That fact is also distinguishable in the comparative analysis between countries (IOCUNESCO 2017).

The predominance of biology and ecology skills could be attributed to the biological training of the principal pioneers who started research in marine science in Uruguay (Davyt 1995). Additionally, the lower cost of acquiring biological information than the funds needed to carry out physical or biogeochemical studies (including vessels, remote sensing networks, or complex laboratory equipment) (NRC 2015) could have influenced biological studies' greater development.

The leading journals in which authors with affiliation from Uruguay publish their papers also reflect the bias towards biological issues throughout the period studied. In the first phase analyzed, journals related to the exploitation of aquatic resources predominate. In the second decade, more general publications of marine biology and ecology predominate, while in the last decade, the emergence of journals published in Latin America is highlighted. There are no specialized journals in marine physics and geochemistry among the most important sources of each decade.

\section{Collaboration networks: co-authorships analysis}

The co-authorship networks analysis shows the development of the Uruguayan academics' community focused on various aspects of marine science. In the three periods analyzed, the central role that authors with a more outstanding production of articles play is highlighted (Fig. 3, see also Table 4), which generally occupy the central node of the groupings. These authors can be identified as professors of the university with an extensive career, and several of them are pioneers in the discipline. The increasing number of authors is also notable, especially in the last decade, leading to the development of new co-authors groups (investigating new areas), which aligns with what was expected in academic networks' growth. It has been suggested that these networks grow by adding new connections so that the probability that an individual gains a new connection is proportional to the number of connections they already have (Newman 2004). It can also be related to the fact that in the first period studied, the coauthors' groupings were virtually disconnected, becoming increasingly interconnected as time elapsed. In the second period, there is an important international collaboration, where several sub-networks made up of foreign co-authors are evident, but in the last period studied, the connections between co-authors of Uruguay gain strength as connections with foreign coauthors decrease, coincident with that indicated by the analysis of the number of mentions to foreign institutions in co-authored works (see above) by researchers from Uruguay.

\section{Limitations}

This contribution presents some limitations, both conceptual and methodological. In the first case, it must be recognized that the generation of publications is not necessarily a faithful reflection of the advance of knowledge in a given scientific discipline (for example, 
there may be some redundancy in the scientific advances generated by different articles). On the other hand, this work results do not necessarily reflect the increase of knowledge about Uruguay's marine ecosystems. Our approach (based on the country of affiliation) does not allow us to distinguish how many of the articles included in the collection are focused on the environments within the Uruguayan territory, nor does it allow the number of works with Uruguayan authors focusing on foreign territories to be discerned.

As methodological limitations, we highlight using a single bibliographic database (Scopus), which could produce a bias in selecting articles for this work. However, several comparative studies between Scopus and other bases (e.g. WoS and Publimed) highlight the remarkable coincidence in the records contained in Scopus, even concluding that WoS behaves like a subset of the references contained in Scopus, with more than $97 \%$ matches existing (Visser \& Moed 2008). On the other hand, the present work does not consider the generation of knowledge in marine science disciplines embodied in non-indexed publications such as graduate and postgraduate theses, technical reports, presentations at scientific events, or nationally published books.

\section{Conclusions and perspectives}

The marine science carried out by Uruguayan authors has been developing since the 1970s, beginning their notoriety in the databases of articles published in refereed international journals since the beginning of the 1990s. Several indicators show an increase in scientific activity accompanied by the academic system's increasing complexity from that moment to the present. However, during the last five years, the number of articles has oscillated between 64 and 76, not growing beyond that point. This greater dynamism is related to the university's budget and other indicators of the country's economic growth and international cooperation, especially in the early stages recorded in this study. The research system of marine science shows a notable institutional centralization in UDELAR and within it in a few research groups led by no more than five predominant authors in the number of articles and citations received.

Additionally, there is an excellent knowledge generation in biological and ecological aspects, with much less physical aspects and virtually no research groups producing articles focused on geology, chemistry, geophysics, and other disciplines. Within marine biology, knowledge focuses particularly on coastal ecosystems, planktonic and benthic environments, commercial fish, and large vertebrates' conservation biology. However, beyond the evident increase in scientific activity in marine science in Uruguay, the degree of development does not seem sufficient to address the main emerging issues of the discipline, which was recently outlined in the international agenda (NRC 2015, IOC-UNESCO 2017).

In that context, our review shows that Uruguay has adequate human resources capacities to produce knowledge related to biological aspects such as the evaluation of the marine environment, the ecology of benthos and plankton, and the evaluation of fish populations. There are limited human resources to examine the ocean's physical structure and the oceanatmosphere interconnection, both of which are key aspects to understanding climate change (IOCUNESCO 2017). However, the country does not demonstrate the capabilities to assess the hydrological cycle's influence and land use in coastal systems' biogeochemical cycles. There are also no research teams focused on characterizing the ocean floor's geophysical and chemical aspects (regardless of seismic oil prospections) and answering questions regarding the state and evolution of ocean basins. Finally, there is no evidence of the capacity to investigate how society relates to marine ecosystems comprehensively.

Suppose the State of Uruguay intends to promote the development of marine science. In that case, longterm scientific policy strategies will be necessary at a national level, ideally governed by a new non-sectorial institutional framework to promote and articulate the efforts of all non-government and government organizations involved in the marine space (Ehler \& Douvere 2009). Although the increase of funds devoted to research in marine science is fundamental, another necessary aspect to consider stimulating discipline development is to encourage international cooperation. It would be unfeasible to access the latest technology required to investigate the vastness of the oceans.

\section{ACKNOWLEDGMENTS}

Thanks to colleagues from UNDECIMAR who provided insights and expertise that greatly assisted this manuscript and the friendship necessary to keep going. Especial appreciation for the comments and corrections made by my beloved Diana Szteren, and my friend Danilo Calliari, to the first draft of this work. This research was partially supported by CSIC-Grupos $\left(\mathrm{N}^{\circ} 32\right)$, CSIC VUSP M2, PEDECIBA, and SNI ANII.

\section{REFERENCES}

Adams, J. 2013. Collaborations: the fourth age of research. Nature, 497: 557-560. 
Aksnes, D.W. \& Browman, H.I. 2016. An overview of global research effort in fisheries science. ICES Journal of Marine Science, 73: 1004-1011.

Aria, M. \& Cuccurullo, C. 2017. Bibliometrix: an R-tool for comprehensive science mapping analysis. Journal of Informetrics, 11: 959-975.

Arocena, R. 2017. Fostering the developmental role of the university in Uruguay. In: Brundenius, C., Göransson, B. \& De Mello, J.M.C. (Eds.). Universities, inclusive development and social innovation. Springer, Cham, pp. 179-198.

Beck, M.W., Brumbaugh, R.D., Airoldi, L., Carranza, A., Coen, L.D., Crawford, C., et al. 2011. Oyster reefs at risk globally and recommendations for ecosystem revitalization. BioScience, 61: 107-116.

Bertullo, E. 2005. El sector industrial pesquero análisis de política sectorial. Boletín del Instituto de Investigaciones Pesqueras, 25: 1-99.

Boltovskoy, D. \& Valentin, J. 2018. Overview of the history of biological oceanography in the southwestern Atlantic, with emphasis on plankton. In: Hoffmeyer, M., Sabatini, M., Brandini, F., Calliari, D. \& Santinelli, N. (Eds.). Plankton. Ecology of the southwestern Atlantic: from the subtropical to the subantarctic realm. Springer, Berlin, pp. 3-34.

Bornmann, L. \& Mutz, R. 2015. Growth rates of modern science: a bibliometric analysis based on the number of publications and cited references. Journal of the Association for Information Science and Technology, 66: 2215-2222.

Borrett, S.R., Sheble, L., Moody, J. \& Anway, E.C. 2018. Bibliometric review of ecological network analysis: 2010-2016. Ecological Modelling, 382: 63-82.

Charles, K. 2017. Marine science and blue growth: assessing the marine academic production of 123 cities and territories worldwide. Marine Policy, 84: 119-129.

Commission on the Limits of the Continental Shelf. 2016. Summary of recommendations of the Commission on the Limits of the Continental Shelf in regard to the submission made by the oriental republic of Uruguay. United Nations Convention on the Law of the Sea, Montego Bay.

Consejo Directivo Central de la Universidad de la República (CDC). 2008. Sesión ordinaria de fecha 25 de noviembre de 2008, Número 5 (Exp. 001000002969-08).

Courtial, J.P., Callon, M. \& Laville, F. 1991. Co-words analysis as a tool for describing the networks of interaction between basic and technological resear- ches: the case of polymer chemistry, Scientometrics, 22: $155-205$.

Davyt, A. 1995. Las ciencias del mar en el marco de la Facultad de Ciencias: la carrera de Oceanografía Biológica (1978-1994) y la inserción laboral de sus egresados. Tesis de Oceanografía Biológica, Universidad de la República, Montevideo.

Defeo, O. \& De Alava, A. 1995. Effects of human activities on long-term trends in sandy beach populations: the wedge clam Donax hanleyanus in Uruguay. Marine Ecology Progress Series, 123: 73-82.

Defeo, O. \& McLachlan, A. 2005. Patterns, processes and regulatory mechanisms in sandy beach macrofauna: a multi-scale analysis. Marine Ecology Progress Series, 295: 1-20.

Defeo, O., Jaramillo, E. \& Lyonnet, A. 1992. Community structure and intertidal zonation of the macroinfauna on the Atlantic coast of Uruguay. Journal of Coastal Research, 8: 830-839.

Defeo, O., McLachlan, A., Schoeman, D., Schlacher, T., Dugan, J., Jones, A., et al. 2009. Threats to sandy beach ecosystems: a review. Estuarine Coastal and Shelf Science, 81: 1-12.

Delecroix, B. \& Eppstein, R. 2004. Co-word analysis for the non-scientific information example of Reuter's business briefings. Data Science Journal, 3: 1-90.

Díaz, A.F., Studzinski, C.D. \& Mechoso, C.R. 1998. Relationships between precipitation anomalies in Uruguay and southern Brazil and sea surface temperature in the Pacific and Atlantic Oceans. Journal of Climate, 11: 251-271.

Dulvy, N.K., Baum, J.K., Clarke, S., Compagno, L.J., Cortés, E., Domingo, A., et al. 2008. You can swim but you can't hide: the global status and conservation of oceanic pelagic sharks and rays. Aquatic Conservation: Marine and Freshwater Ecosystems, 18: 459482.

Edelmann, A., Moody, J. \& Light, R. 2017. Disparate foundations of scientists' policy positions on contentious biomedical research. Proceedings of the National Academy of Sciences, 114: 6262-6267.

Egghe, L. 2006. Theory and practice of the g-index. Scientometrics, 69: 131-152.

Ehler, C. \& Douvere, F. 2009. Planificación espacial marina. Una guía paso a paso hacia la gestión ecosistémica. Comisión Oceanográfica Intergubernamental y el Programa del Hombre y la Biosfera. COI Manuales y Guías, 53, UNESCO, Paris.

Frazzetto, G. 2004. The changing identity of the scientist. EMBO Reports, 5: 18-20. 
García-Alonso, J., Lercari, D. \& Defeo, O. 2019. The Río de la Plata as a neotropical estuarine system. In: Wolanski, E., Day, J., Elliott, M. \& Ramachandran, R. (Eds.). Coasts and estuaries: the future. Elsevier, Amsterdam, pp. 45-56.

Gutiérrez, N.L., Hilborn, R. \& Defeo, O. 2011. Leadership, social capital and incentives promote successful fisheries. Nature, 470: 386.

Hirsch, J.E. 2005. An index to quantify an individual's scientific research output. Proceedings of the National Academy of Sciences, 102: 16569-16572.

Instituto Nacional de Impresiones y Publicaciones Oficiales (IMPO) - Centro de Información Oficial. 2009. Reestructura de la Comisión Nacional de Oceanología. Decreto $N^{\circ} 353 / 009$. Registro Nacional de Leyes y Decretos, 1: 258-258.

Intergovernmental Oceanographic Commission - United Nations Educational, Scientific and Cultural Organization (IOC-UNESCO). 2017. Global ocean science report. The current status of ocean science around the world. UNESCO Publishing, Paris.

Klappenbach, M.A. \& Scarabino, V. 1969. El borde del mar. Editorial Nuestra Tierra, Montevideo.

Lauro, F.M., Senstius, S.J., Cullen, J., Neches, R., Jensen, R.M., Brown, M.V. et al. 2014. The common oceanographer: crowdsourcing the collection of oceanographic data. Plos Biology, 12: e1001947.

Marín, Y.H. 2016. La pesca industrial uruguaya desde la perspectiva de los sistemas social-ecológicos. Tesis de Magíster, Universidad de la República, Montevideo.

Martínez, C.M. \& Fournier, R. 1999. EcoPlata: an Uruguayan multi-institutional approach to integrated coastal zone management. Ocean \& Coastal Management, 42: 165-185.

McCullagh, P. \& Nelder, J.A. 1989. Generalized linear models of monographs on statistics and applied probability. Vol. 37. Chapman and Hall, London.

McLachlan, A., Dugan, J.E., Defeo, O., Ansell, A.D., Hubbard, D.M., Jaramillo, E. \& Penchaszadeh, P.E. 1996. Beach clam fisheries. Oceanography and Marine Biology: An Annual Review, 34: 163-232.

Ministerio de Educación y Cultura (MEC). 2014. Memoria institucional 2010-2014. Ministerio de Educación y Cultura, Montevideo, 304 pp. [http:// www.mec.gub.uy/innovaportal/file/59735/1/memoria -mec-para-web.pdf]. Reviewed: March 10, 2020.

Melin, G. \& Persson, O. 1996. Studying research collaboration using co-authorships. Scientometrics, 36: 363-377.

Ministerio de Ganadería, Agricultura y Pesca (MGAP). 2009. Informe de transición. MGAP, Montevideo, 35 pp. [http://archivo.presidencia.gub.uy/sci/MEM 2010/informe_transicion .pdf]. Reviewed: March 10, 2020.
Moody, J. 2004. The structure of a social science collaboration network: disciplinary cohesion from 1963 to 1999. American Sociological Review, 69: 213-238.

Moody, J. \& Light, R. 2006. A view from above: the evolving sociological landscape. American Sociologist, 37: 67-86.

Newman, M.E. 2004. Co-authorship networks and patterns of scientific collaboration. Proceedings of the National Academy of Sciences, 10: 5200-5205.

Nielsen-Muñoz, V., Azofeifa-Mora, A.B., RomeroChaves, R. \& Wehrtmann, I.S. 2018. Bibliometry of marine science and limnology publications (19792015) by the Centro de Investigación en Ciencias del Mar y Limnología (CIMAR), Universidad de Costa Rica. Revista de Biología Tropical, 66: 1-23.

National Research Council (NRC). 2015. Seachange: 2015-2025. Decadal survey of ocean sciences. National Academies Press, Washington, DC.

Peters, H. \& Van Raan, A. 1991. Structuring scientific activities by co-author analysis: an exercise on a university faculty level. Scientometrics, 20: 235-255.

Piola, A.R., Campos, E.J.D., Möller Jr., O.O., Charo, M. \& Martinez, C. 2000. Subtropical shelf front off eastern South America. Journal Geophysical Research Oceans, 105: 6565-6578.

Price, D.J. 1961. Science since Babylon. Yale University Press, New Haven.

R Core Team. 2016. R: A language and environment for statistical computing. R Foundation for Statistical Computing. [http://www.R-project.org/]. Reviewed: March 12, 2020.

Rousseau, D.M. 2012. The Oxford handbook of evidencebased management. Oxford University Press, Oxford.

Santini, J. 2011. Alerta: la pesca se agota. Vadenuevo, Política, Economía Sociedad y Cultura, 29.

Tabah, A.N. 1999. Literature dynamics: studies on growth, diffusion, and epidemics. Annual Review of Information Science and Technology, 34: 249-286.

United Nations Educational, Scientific and Cultural Organization (UNESCO). 2015. Global investments in R\&D. UNESCO Institute for Statistics Fact Sheet, Paris.

Universidad de la República (UDELAR). 2016. Estadísticas básicas 2016 de la Universidad de la República. Universidad de la República, Montevideo.

Van Eck, N.J. \& Waltman, L. 2007. VOS: a new method for visualizing similarities between objects. In: Lenz, H.-J. \& Decker, R. (Eds.). Advances in data analysis. Proceedings of the $30^{\text {th }}$ Annual Conference of the 
German Classification Society. Springer, Berlin, pp. 299-306.

Visser, M.S. \& Moed, H.F. 2008. Comparing Web of Science and Scopus on a paper-by-paper basis. In: Excellence and emergence. A new challenge for the combination of quantitative and qualitative approaches. Proceedings of the 10th International Conference on Science and Technology Indicators, pp. 23-25.

Received: June 3 2020; Accepted: July 282020 